\title{
Islet-associated macrophages in type 2 diabetes
}

\author{
S. J. Richardson • A. Willcox • A. J. Bone • \\ A. K. Foulis • N. G. Morgan
}

Received: 21 January 2009 /Accepted: 14 May 2009/Published online: 6 June 2009

(C) Springer-Verlag 2009

Keywords $\mathrm{CD}^{+} 8^{+}$cells $\cdot$ Enteroviral capsid protein vp1 . Inflammation · Protein kinase R · Type 2 diabetes

To the Editor: Recently evidence has emerged that supports a role for islet inflammation in the development of type 2 diabetes in man, suggesting that there may be certain common features underlying the pathology of beta cell loss in both type 1 and type 2 diabetes. In particular, data have recently been presented revealing an increased number of macrophages infiltrating the islets of nine type 2 diabetic patients, as well as in several animal models of type 2 diabetes (including high-fat-fed C57BL6/6J mice, GK rats and the $d b / d b$ mouse) when compared with relevant controls [1]. Those authors argued that this evidence implies that macrophage infiltration could be involved in mediating beta cell dysfunction and loss in type 2 diabetes. In view of these conclusions, we considered it important to verify whether increased macrophage infiltration is also

\footnotetext{
S. J. Richardson · A. Willcox $\cdot$ N. G. Morgan $(\bowtie)$ Institute of Biomedical and Clinical Sciences,

Peninsula Medical School,

Tamar Science Park,

Plymouth PL6 8BU, UK

e-mail: noel.morgan@pms.ac.uk

\section{A. J. Bone}

School of Pharmacy and Biomolecular Sciences,

University of Brighton,

Moulescoomb,

Brighton, UK

\author{
A. K. Foulis \\ Department of Pathology, Royal Infirmary, \\ Glasgow, UK
}

observed in a different and larger cohort of human patients with type 2 diabetes and to assess the magnitude of this response.

Serial sections of paraffin-embedded pancreas recovered at autopsy from 15 type 2 diabetic patients (mean age $[ \pm$ SEM] $69.2 \pm 1.8$ years) and 16 non-diabetic controls (age $52.9 \pm 3.9$ years) were processed and stained with antiinsulin and anti-CD68 antibodies (DAKO, Ely, UK) using a standard immunoperoxidase technique. The use of all tissue was undertaken with full ethical permission. A quantitative analysis of up to 50 randomly selected islets per individual was carried out and the number of $\mathrm{CD} 68^{+}$cells (taken to indicate the presence of macrophages) either within the islets or in the peri-islet area was counted. Statistical comparisons were performed by $\chi^{2}$ analysis. Within the control group, we did not observe any tendency for the number of macrophages present within islets to change with age. Therefore we consider that, although the mean age of the type 2 diabetic patients was slightly lower than the controls, this difference per se is unlikely to account for variations in macrophage infiltration. In order to confirm that the number of $\mathrm{CD} 68^{+}$cells counted per islet was not distorted by a change in islet size or area in the patients vs controls, random images were examined from slides stained for insulin from six cases of type 2 diabetes (mean age $62.7 \pm 2.3$ years) and four controls (mean age 64.0 \pm 2.6 years). This revealed that the percentage of pancreatic tissue occupied by endocrine cells was similar in the two groups $(1.99 \pm 0.23 \%$ in type 2 diabetes; $2.17 \pm 0.32 \%$ in controls). In addition, the mean endocrine cell area within the islets was also unchanged in the sections studied, implying that the overall size of the islets was not decreased in the cohort of patients with type 2 diabetes compared with the controls. A total of 545 and 564 islets were analysed 
from the type 2 diabetic cases and non-diabetic controls, respectively. Further analysis of the results revealed that very few macrophages were localised within a given islet section in either group of individuals. Thus, the mean number of $\mathrm{CD} 8^{+}$cells found in normal islets averaged fewer than a single cell per islet section $(0.52 \pm 0.08$ cells per islet). This was slightly, but significantly, increased to a mean of $1.34 \pm 0.18 \mathrm{CD}^{+} 8^{+}$cells per islet section in the type 2 diabetic cases (Fig. 1a; $p=0.0002$ ). A representative image showing $\mathrm{CD} 68^{+}$-immunopositive cells within an islet from a patient with type 2 diabetes is shown in Fig. 1c.

A critical issue arising from these observations is the biological relevance of this relatively modest rise in macrophage number within the islet milieu. In order to evaluate this, the proportion of islets having more than three $\mathrm{CD} 68^{+}$cells per islet section was previously examined [1] on the basis that this might provide a more robust index of islet inflammation. Using a similar criterion, we observed that $20.6 \pm 4.1 \%$ of the islets examined in patients with type 2 diabetes were inflamed. This compared with $4.6 \pm 1.4 \%$ of islets in non-diabetic individuals (Fig. 1b; $p=$ 0.007). Moreover, we noted that $\mathrm{CD} 68^{+}$macrophages were frequently located among the endocrine cells within the islets of the type 2 diabetic cases, whereas they were usually distributed more peripherally in the islets of nondiabetic controls.

During a parallel analysis of islet inflammation in human type 1 diabetes, we considered it important to define a still more stringent threshold for insulitis and a minimum of five immune cells per islet was selected [2]. If this criterion is employed in the present analysis, the proportion of islets considered to be inflamed is inevitably lower but a significant difference is still noted between the number of $\mathrm{CD} 8^{+}$cells seen within the islets in type 2 diabetes vs controls $(5.6 \pm 1.4 \%$ vs $0.6 \pm 0.3 \%$, respectively; $p=0.001)$. Thus, these findings support the evidence in the previous report [1] that an increased proportion of islets are infiltrated by macrophages in patients with type 2 diabetes.

The mechanism(s) by which $\mathrm{CD} 68^{+}$cells are recruited to the islets in type 2 diabetes are unknown but it was reported that medium recovered after in vitro culture of islets from patients with type 2 diabetes was chemotactic to monocytes and neutrophils [1]. This implies that such islets may be induced to secrete chemokines which promote macrophage recruitment. Of interest in this respect is our recent finding [3] that the enteroviral capsid protein vp1, is produced in the islets of patients with type 2 diabetes at a higher frequency than in controls $(40 \%$ vs $13 \% ; p<0.01)$. We suggest, therefore, that consideration should be given to the possibility that a persistent, low-grade enteroviral infection of islet endocrine cells may induce functional changes that contribute to the recruitment of macrophages in some patients with type 2 diabetes. In support of this, during a more detailed analysis of 351 islets in ten patients with type 2 diabetes, we noted a significant correlation between islet inflammation (defined as islets containing more than five $\mathrm{CD} 68^{+}$cells per section) and the production of both vp1 (detected in $34.6 \%$ [nine of 26] of inflamed islets vs $11.1 \%$ [36 of 325] of non-inflamed islets $\left.\left[\chi^{2} p<0.01\right]\right)$ and the double-stranded RNA-activated kinase, protein kinase R a

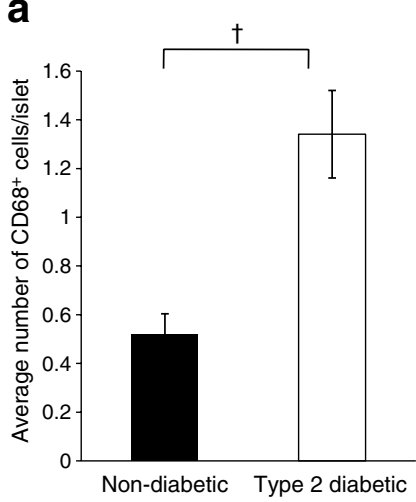

b

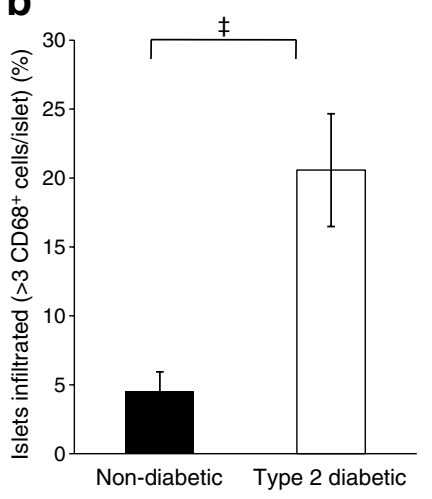

C

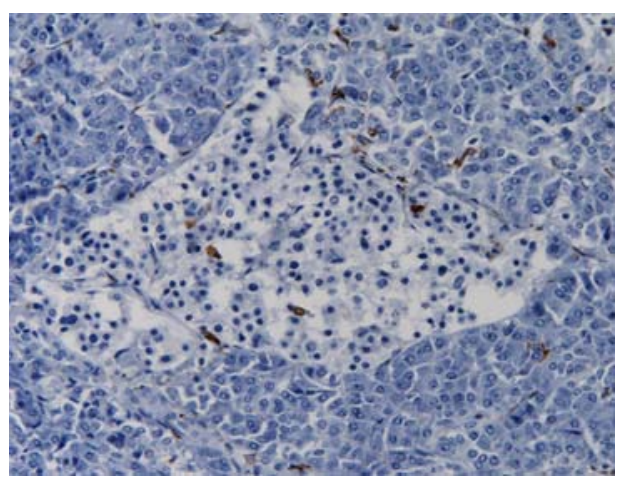

Fig. 1 Increased numbers of $\mathrm{CD} 68^{+}$macrophages were observed in the islets of type 2 diabetic patients when compared with non-diabetic controls. a A detailed analysis of $\mathrm{CD}^{+} 8^{+}$cells in islets from 16 nondiabetic individuals (564 islets in total; white bars) and 15 type 2 diabetic patients (545 islets; black bars) demonstrates that there is an increase in the mean number of $\mathrm{CD} 68^{+}$cells observed per islet section $(\dagger p=0.0002$ ). b The proportion of inflamed islets (defined as those having more than three macrophages per islet section) was also increased in type 2 diabetic patients when compared with non-diabetic controls $(\$ p=0.007)$. a, b Values are means \pm SEM. c A representative image of an islet from a patient with type 2 diabetes revealing the presence of infiltrating macrophages. These were labelled with antiCD68 antiserum and are stained brown 
(present in 50\% [13 of 26] of inflamed islets vs 16.9\% (55 of 325) of non-inflamed islets $\left.\left[\chi^{2} p<0.001\right]\right)$.

Acknowledgements We thank Diabetes UK, the Juvenile Diabetes Research Foundation (JDRF), the European Foundation for the Study of Diabetes (EFSD) and the Coordinated Action of the European Union (Type ONE Coordinated Action [TONECA]) for financial support.

Duality of interest The authors declare that there is no duality of interest associated with this manuscript.

\section{References}

1. Ehses JA, Perren A, Eppler E et al (2007) Increased number of isletassociated macrophages in type 2 diabetes. Diabetes 56:2356-2370

2. Willcox A, Richardson SJ, Bone AJ, Foulis AK, Morgan NG (2009) Analysis of islet inflammation in human type 1 diabetes. Clin Exp Immunol 155:173-181

3. Richardson SJ, Willcox A, Bone AJ, Foulis AK, Morgan NG (2009) The prevalence of enteroviral vp1 immunostaining in pancreatic islets in human type 1 diabetes. Diabetologia doi:10.1007/ s00125-009-1276-0 